\title{
Sistem Akuntansi Penjualan Pada Toko Bangunan Impian Kaliwungu
}

Edy Siswanto $^{1}$, Haris Ihsanil Huda ${ }^{2}$, Eko Siswanto ${ }^{3}$

${ }^{1}$ Komputerisasi Akuntansi STEKOM, Semarang, e-mail: edy@stekom.ac.id

${ }^{2}$ Komputerisasi Akuntansi STEKOM, Semarang, e-mail: haris@stekom.ac.id

${ }^{3}$ Komputerisasi Akuntansi STEKOM, Semarang, e-mail: eko.siswanto@stekom.ac.id

\begin{tabular}{|c|c|}
\hline ARTICLE INFO & ABSTRACT \\
\hline Article history: & \\
\hline $\begin{array}{l}\text { Received } 30 \text { Mei } 2020 \\
\text { Received in revised form } 2 \text { Juni } 2020 \\
\text { Accepted } 10 \text { Juni } 2020 \\
\text { Available online } 12 \text { Juni } 2020\end{array}$ & $\begin{array}{l}\text { Kaliwungu Dream Building Shop is a } \\
\text { business engaged in the sale of building materials } \\
\text { and building-producing tools. This trading business } \\
\text { sells various materials and tools for building } \\
\text { buildings such as sand, cement, nails, paint, } \\
\text { hammers and so on. The Dream Building Shop was } \\
\text { founded by Mr. Zaenal, whose address is Jalan Raya } \\
\text { Sekopek No. } 10 \text { Sarirejo Kaliwungu, Kendal } \\
\text { Regency. } \\
\text { Kaliwungu Dream Building Shop in } \\
\text { recording sales transactions, purchases and reports - } \\
\text { reports still use the manual method by writing them } \\
\text { into a book, this method still requires time which is } \\
\text { relatively old and prone to calculation errors, as a } \\
\text { result you have to work } 2 \text { times or even many times } \\
\text { to recalculate transactions that occur. Factors that } \\
\text { are generally controlled are human errors that occur } \\
\text { in cooking data and storing \& maintaining paper- } \\
\text { shaped documents, where this is very difficult to } \\
\text { overcome. In addition, the process of searching for } \\
\text { data or inventory is also less effective and efficient. } \\
\text { also affect customers, even though performance } \\
\text { according to the store is needed to satisfy customers. }\end{array}$ \\
\hline
\end{tabular}

Keywords: sale of building materials, sales information system

\section{Introduction}

Teknologi kabar ketika ini mengalami perkembangan yg relatif pesat \& kebutuhan insan jua semakin bertambah dan konflik yg dihadapi semakin kompleks. Komputer dalam ketika ini poly dipakai sang instansi pada aneka macam bidang buat merampungkan konflik - konflik yg mereka hadapi. Hal ini mendorong para pakar buat menyebarkan acara - acara personal komputer supaya bisa membantu kinerja insan. Teknologi \& kabar adalah 2 hal yg nir bisa dipisahkan satu sama lainnya.

Toko Bangunan Impian Kaliwungu adalah sebuah bisnis yg beranjak dalam penjualan bahan bangunan \& perkakas penghasil bangunan. Usaha dagang ini menjual aneka macam bahan 
\& perkakas buat menciptakan bangunan misalnya pasir, semen, paku, cat, palu \& sebagainya. Toko Bangunan Impian didirikan sang Bapak Zaenal, yg beralamatkan pada Jalan Raya Sekopek No 10 Sarirejo Kaliwungu, Kabupaten Kendal.

Toko Bangunan Impian Kaliwungu pada pencatatan transaksi penjualan, pembelian dan laporan - laporan masih memakai cara manual menggunakan menuliskannya kedalam kitab cara ini masih membutuhkan saat yg relatif usang \& rentan terhadap kesalahan perhitungan, sebagai akibatnya wajib kerja 2 kali atau bahkan berkali - kali buat menghitung ulang transaksi yg terjadi. Faktor lebih banyak didominasi yaitu kesalahan insan poly terjadi pada memasak data dan penyimpanan \& perawatan dokumen berbentuk kertas, dimana hal ini sangat sulit ditanggulangi Selain itu pada proses pencarian data atau persediaan barang jua kurang efektif \& efisien, hal ini

Hal ini berpengaruh terhadap pelanggan, padahal dibutuhkan kinerja berdasarkan toko tadi bisa memuaskan pelanggan.

Didalam Teknologi Informasi masih ada aplikasi yg dipakai buat merampungkan perkara diatas aplikasi tadi yaitu pelaksanaan Microsoft Visual Basic 6.0. Microsoft Visual Basic 6.0 dipilih buat diimplementasikan dalam Toko Bangunan Impian Kaliwungu, lantaran Microsoft Visual Basic 6.0 merupakan bahasa pemrograman yg dipakai buat menciptakan pelaksanaan windows yg berbasis grafis. Aplikasi ini cocok diterapkan buat proses penjualan \& persediaan / inventory. Diharapkan penerapan pelaksanaan Microsoft Visual Basic 6.0 dalam Toko Bangunan Impian Kaliwungu akan berjalan baik.

Dengan adanya konflik yg demikian, maka dibutuhkan perubahan sistem berdasarkan cara yg manual sebagai cara terkomputerisasi, sebagai akibatnya bisa memudahkan pada pencatatan transaksi penjualan juga pembelian.

Dari uraian konflik diatas, maka penulis merogoh judul "SISTEM KOMPUTERISASI PENJUALAN PADA TOKO BANGUNAN IMPIAN KALIWUNGU" Sistem komputerisasi ini diharapkan bisa menaruh kemudahan - kemudahan pada memperoleh warta yg dibutuhkan.

\section{Landasan Teori}

\subsection{Sistem}

Sistem adalah suatu jaringan prosedur yang dibuat menurut pola yang terpadu untuk melaksanakan kegiatan pokok perusahaan. Prosedur adalah suatu urutan kegiatan klerikal, biasanya melibatkan beberapa orang dalam satu departemen atau lebih yang dibuat untuk menjamin penanganan serta seragam transaksi perusahaan yang terjadi berulang-ulang. (Mulyadi,2013)

"Sistem adalah kumpulan dari sub sistem/ bagian / komponen apapun baik phisik ataupun non phisik yang saling berhubungan satu sama lain dan bekerja secara harmonis untuk mencapai satu tujuan tertentu." (Susanto, 2013)

\subsection{Sistem Informasi}

"Kumpulan dari sub-sub sistem baik phisik maupun non phisik yang saling berhubungan satu sama lain dan bekerja sama secara harmonis untuk mencapai satu tujuan yaitu mengolah data menjadi informasi yang berguna." (Susanto, 2013)

Sistem informasi adalah seperangkat komponen yang saling berhubungan, yang bekerja untuk mengumpulkan dan menyimpan data serta mengolahnya menjadi informasi yang digunakan.(Hartono, 2013)

\subsection{Tujuan Sistem Informasi}

a. Untuk menyediakan Informasi Bagi Usaha Baru

Kebutuhan informasi pada usaha baru sangat penting untuk mampu bersaing dalam dunia usaha.Informasi yang dibutuhkan oleh usaha baru diantaranya informasi mengenai peluang bisnis, bagaimana menghadapi pelanggan, menghadapi komplain, dan bahkan sampai dalam taktik bisnis maupun penjualan sampai dalam pengambilan keputusan dalam segala jenis bagian usaha. 
b. Untuk memperbaiki informasi yang dihasilkan dari sistem yang sudah ada atau sistem lama.

Dalam perusahaan yang baru berjalan sangat dibutuhkan pengembangan. Sistem akuntansi. Pada perusahaan di bidang dagang, jasa, manufaktur sangat memerlukan pengembangan sistem akuntansi lengkap, hal ini berguna agar kegiatan perusahaan berjalan dengan lancar.

c. Untuk memperbaiki sistem pengendalian intern perusahaan sehingga dapat mempermudah menjaga kekayaan perusahaan.

Akuntansi merupakan pertanggungjawaban kekayaan suatu perusahaan atau organisasi. Dalam hal pengembangan sistem akuntansi selalu digunakan untuk memperbaiki perlindungan terhadap kekayaan perusahaan, sehingga pertanggungjawaban terhadap penggunaan kekayaan organisasi dapat dilaksanakan dengan baik.

d. Untuk mengurangi biaya kegiatan klerikal dalam kegiatan akuntansi.

Dalam hal ini informasi dapat dijadikan sebagai barang ekonomi yang mempunyai banyak manfaat, karena untuk memperolehnya diperlukan pengorbanan sumber ekonomi lainnya. Jika pengorbanan untuk memperoleh informasi keuangan diperhitungkan lebih besar dari manfaatnya, maka sistem yang sudah ada perlu dirancang kembali untuk mengurangi pengorbanan sumber daya bagi penyedia informasi tersebut. (Sujarweni, 2015)

\subsection{Kualitas Sistem Informasi Akuntansi}

Pengertian atau definisi kualitas dapat berbeda makna bagi setiap orang, karena kualitas memiliki banyak kriteria dan sangat tergantung pada konteksnya. Berikut ini pengertian Kualitas menurut ISO 9000 dalam Rambat Lupiyoadi: "Degree to which a set of inherent characteristics fulfils requirements(derajat yang dicapai oleh karakter yang inheren dalam memenuhi persyaratan)". Persyaratan dalam hal ini adalah "need expectation that is stated, generally implied or obligatory (kebutuhan atau harapan yang dinyatakan, biasanya tersirat atau wajib)". Kualitas sebagaimana yang diinterpretasikan ISO 9000 merupakan perpaduan antara sifat dan karakteristik yang menentukan sejauh mana keluaran dapat memenuhi persyaratan kebutuhan pengguna.Pengguna yang menentukan dan menilai sampai seberapa jauh sifat dan karakteristik tersebut memenuhi kebutuhannya.

Sistem informasi merupakan komponen-komponen yang bekerja secara terstruktur mengkoordinasikan berbagai sumber daya untuk menghasilkan informasi serta dapat digunakan untuk meningkatkan efisien dan efektifitas dalam pencapaian tujuan perusahaan.Maka untuk dapat mencapai tujuan perusahaan secara efektif dan efisien dibutuhkan kualitas sistem informasi yang baik.Salah satunya adalah sistem informasi akuntansi.(Rambat,2013)

\subsection{Pengertian Akuntansi}

Menurut Kartikahadi, "Akuntansi dapat diartikan sebagai sistem informasi yang menyediakan laporan untuk para pemangku kepentingan mengenai aktivitas ekonomi dan kondisi perusahaan".(Kartikahadi 2016)

Menurut Sumarsan "Akuntansi adalah suatu seni mengumpulkan, mengidentifikasikan, mengklarifikasikan, mencatat tranasksi serta kejadian yang berhubungan dengan keuangan sehingga dapat digunakan oleh pihak - pihak yang berkepentingan. (Sumarsan, 2013)

\subsection{Pengertian Penjualan}

Penjualan adalah suatu sistem keseluruhan dari kegiatan usaha yang ditujukan untuk merencanakan ,menentukan harga, mempromosikan dan mendistribusikan barang, jasa, ide kepada pasar sasaran agar dapat mencapai tujuan organisasi. (Sarjono,2016) 
"Penjualan adalah kegiatan yang terdiri dari penjualan barang atau jasa baik secara kredit maupun secara tunai." Maka dari itu dapat disimpulkan bahwa Sistem Informasi Penjualan adalah sub sistem informasi bisnis yang mencakup kumpulan prosedur yang mencatat, melaksanakan, menghitung, membuat dokumen dan informasi penjualan untuk keperluan manajemen dan bagian lain yang berkepentingan dalam perusahaan, mulai dari diterimanya order penjualan perusahaan sampai mencatat timbulnya piutang dagang. (Mulyadi, 2016).

Tables and Figures are presented center, as shown below and cited in the manuscript.

\section{Results and Analysis}

Perancangan sistem dapat didefinisikan sebagai penggambaran, perencanaan dan pembuatan sketsa atau pengaturan dari beberapa elemen terpisah kedalam satu kesatuan yang utuh dan berfungsi. Implementasi sistem diartikan proses pengecekan suatu sistem yang dihasilkan sudah dapat dijalankan sesuai dengan apa yang diharapkan Adapun hasil sistem yang penulis hasilkan adalah sebagai berikut :

a. Tampilan Menu Login

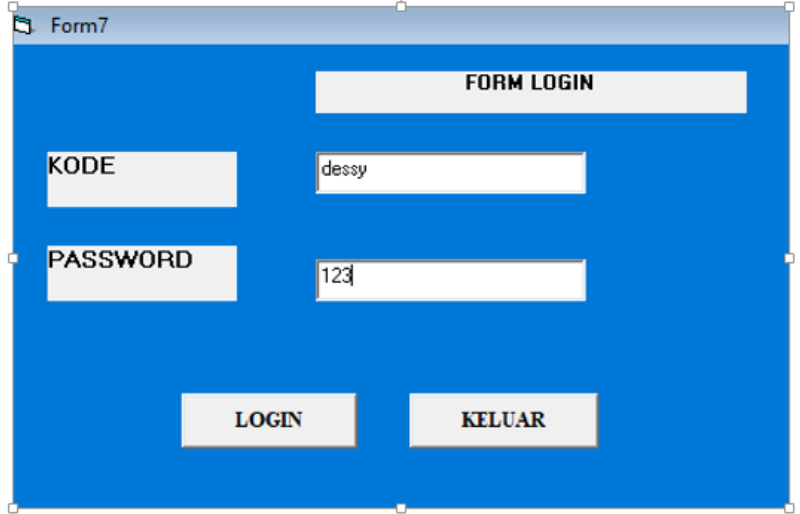

Gambar 1 Tampilan Form Login

Form login merupakan bagian dari menu file yang berfungsi untuk masuk ke program, terdiri dari kode dan password.

b. Tampilan Form Menu Utama

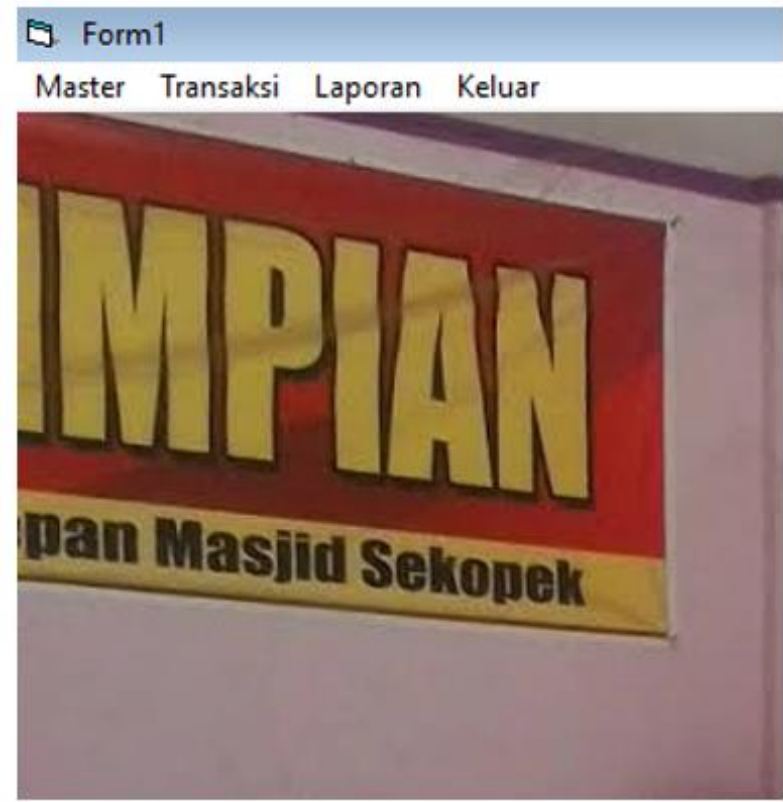

Gambar 2 Tampilan form menu utama

JURNAL ILMIAH KOMPUTERISASI AKUNTANSI Vol. 13, No. 1, Juli 2020 : 121-128 
Menu utama terdiri dari menu master, transaksi, laporan dan keluar.Menu master memiliki 3 form yaitu form data supplier, form data barangdan data pelanggan, menu transaksi yaitu form pembelian dan penjualan, menu laporan yaitu Lap. Barang, Lap. Supplier, Lap.Pembelian dan juga Lap. Penjualan.

c. Tampilan Form Data Barang

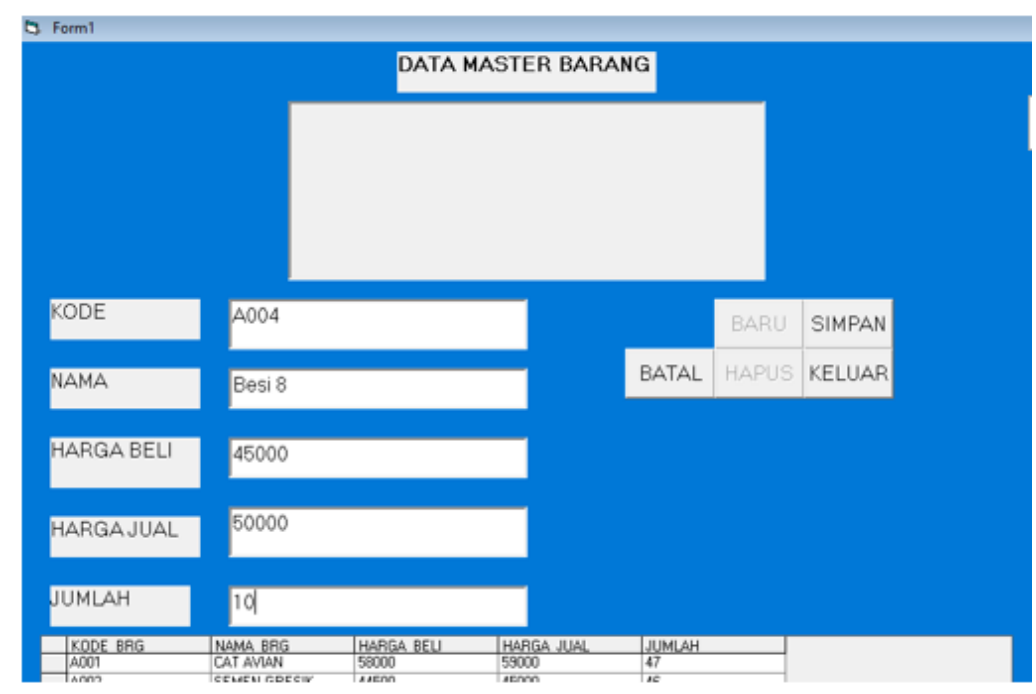

Gambar 3 Tampilan form data barang

Form data barang digunakan untuk menginput data barang terdiri dari kode barang, nama barang, harga dan harga jual total.

d. Tampilan Form Data Suplier

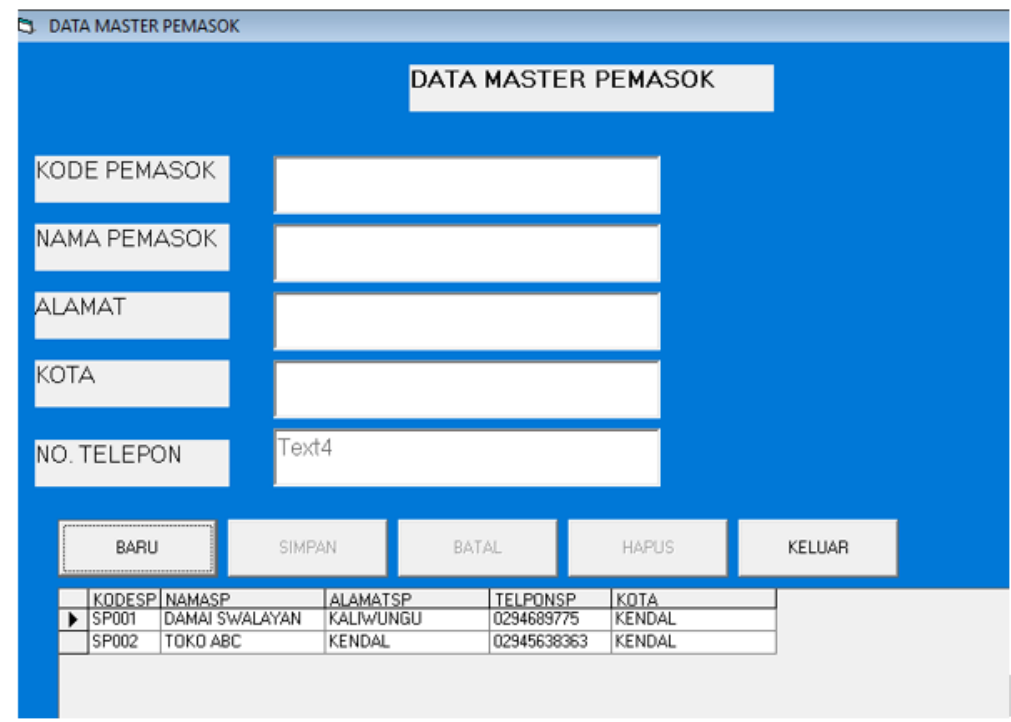

Gambar 4 Tampilan form data suplier

Form data supplier digunakan untuk menginput data supplier terdiri dari kode suplier, nama suplier, alamat dan no telpon suplier. 
e. Tampilan Form Transaksi Penjualan

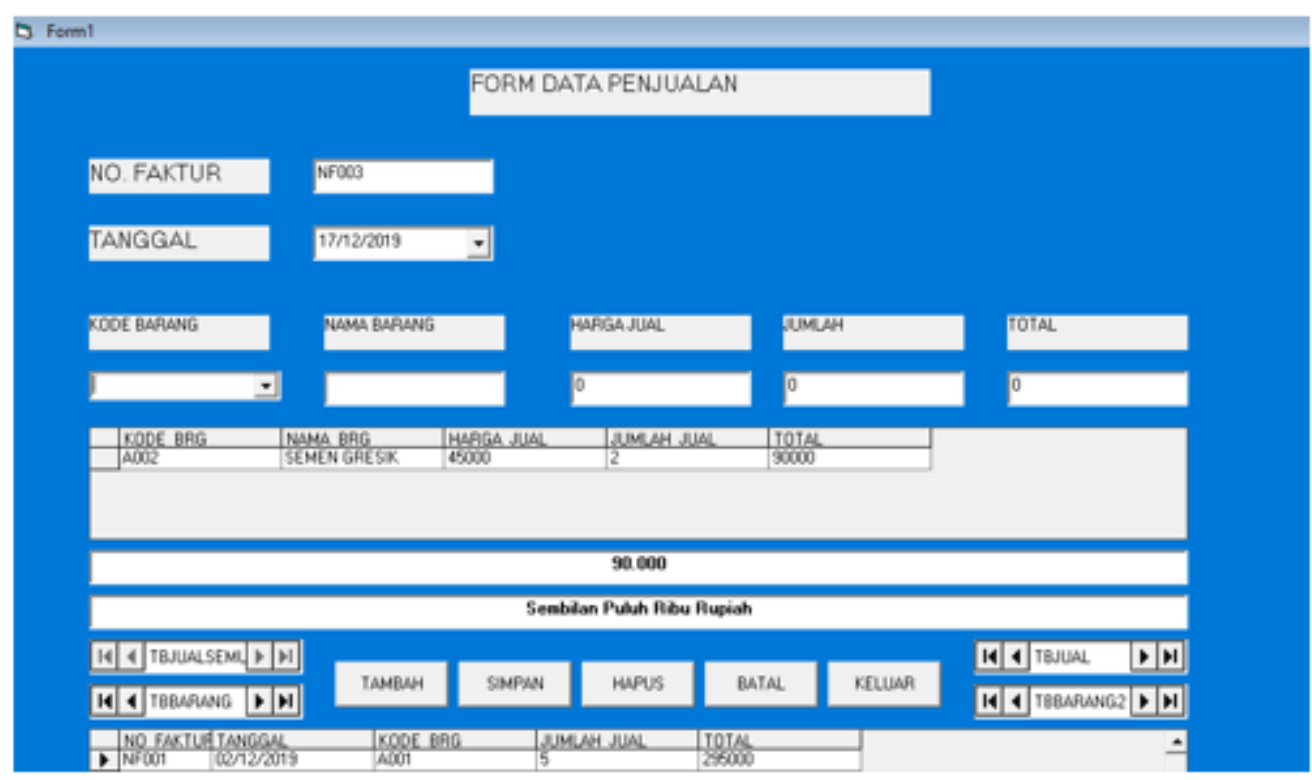

Gambar 5 TampilanForm Penjualan

f. Tampilan Form Pelanggan

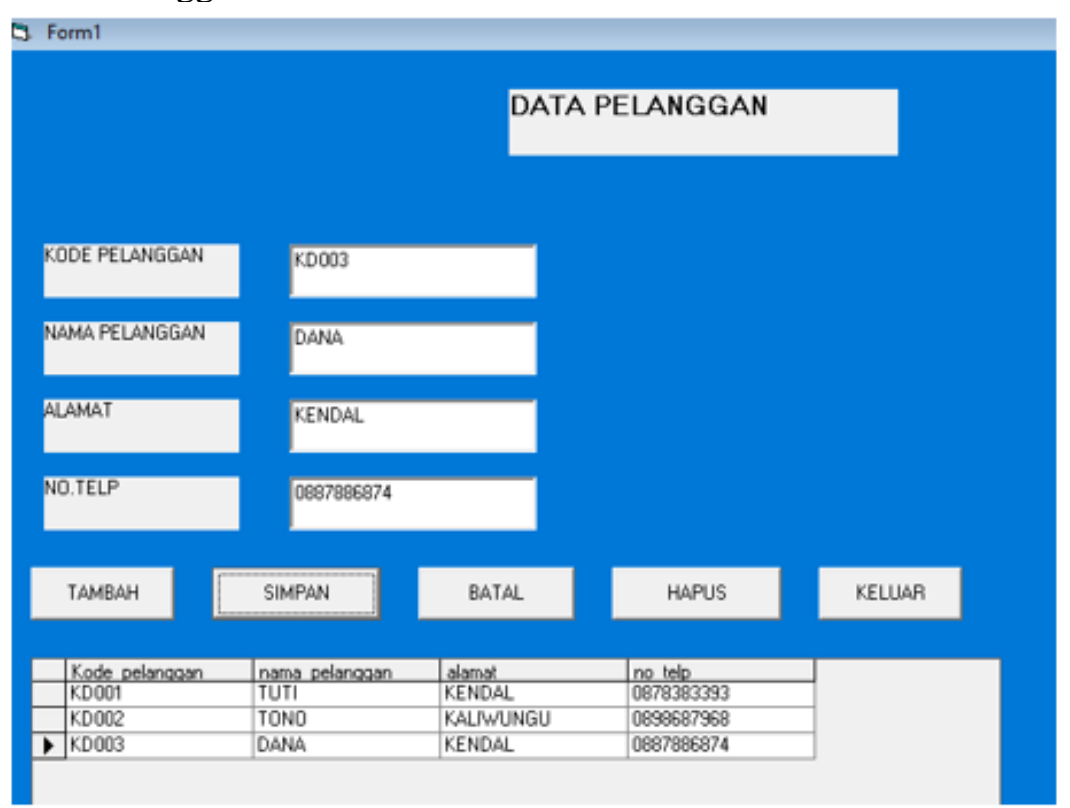

Gambar 6 TampilanForm Pelanggan

JURNAL ILMIAH KOMPUTERISASI AKUNTANSI Vol. 13, No. 1, Juli $2020: 121$ - 128 
g. Tampilan Form Pembelian

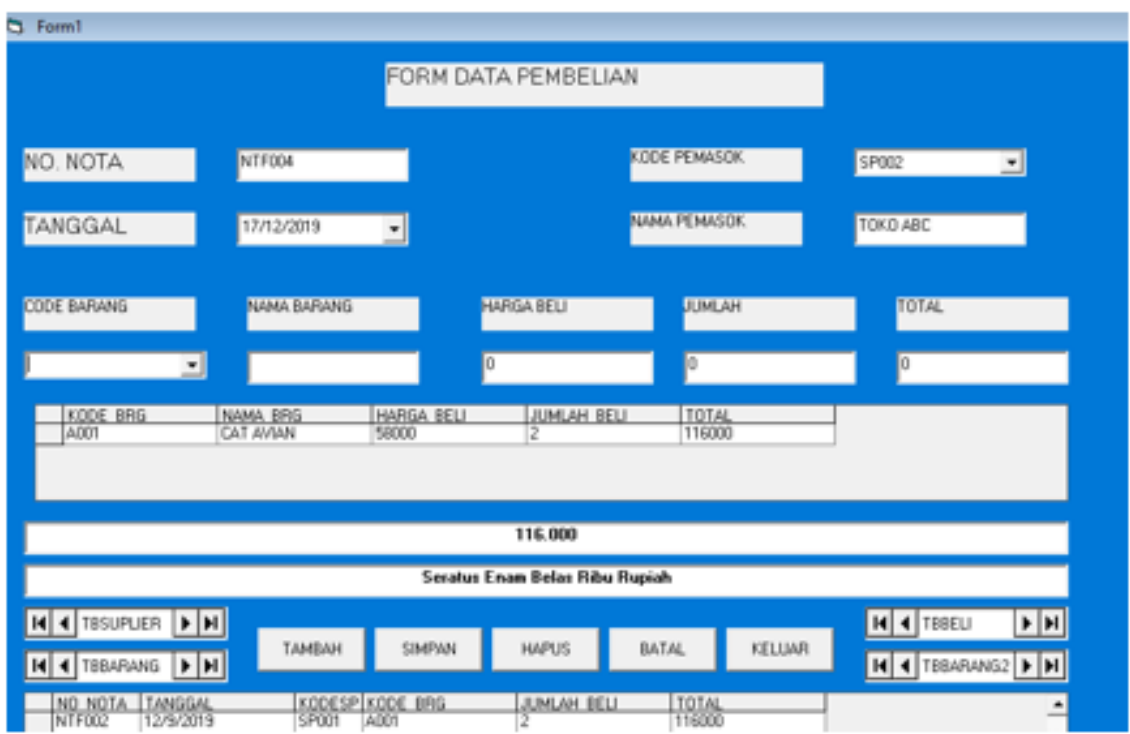

Gambar 7 TampilanForm Pembelian

h. Tampilan Laporan Data Barang

\begin{tabular}{|c|c|c|c|c|}
\hline \multirow[b]{2}{*}{$\frac{\text { KODEBRG }}{\text { A0001 }}$} & \multicolumn{3}{|c|}{ LAPORAN DATA BARANG } & \\
\hline & $\frac{\text { SAMABRG }}{\text { SEMEN }}$ & $\begin{array}{l}\text { BARGABELI } \\
44.000\end{array}$ & $\frac{\text { BARGAJCAL }}{45.000}$ & $\frac{\text { ToTAL }}{1000}$ \\
\hline
\end{tabular}

Kendal, 3 Agustes 2019

Petupas

Gambar 8 Tampilan Laporan Data Barang

i. Tampilan Laporan Penjualan 


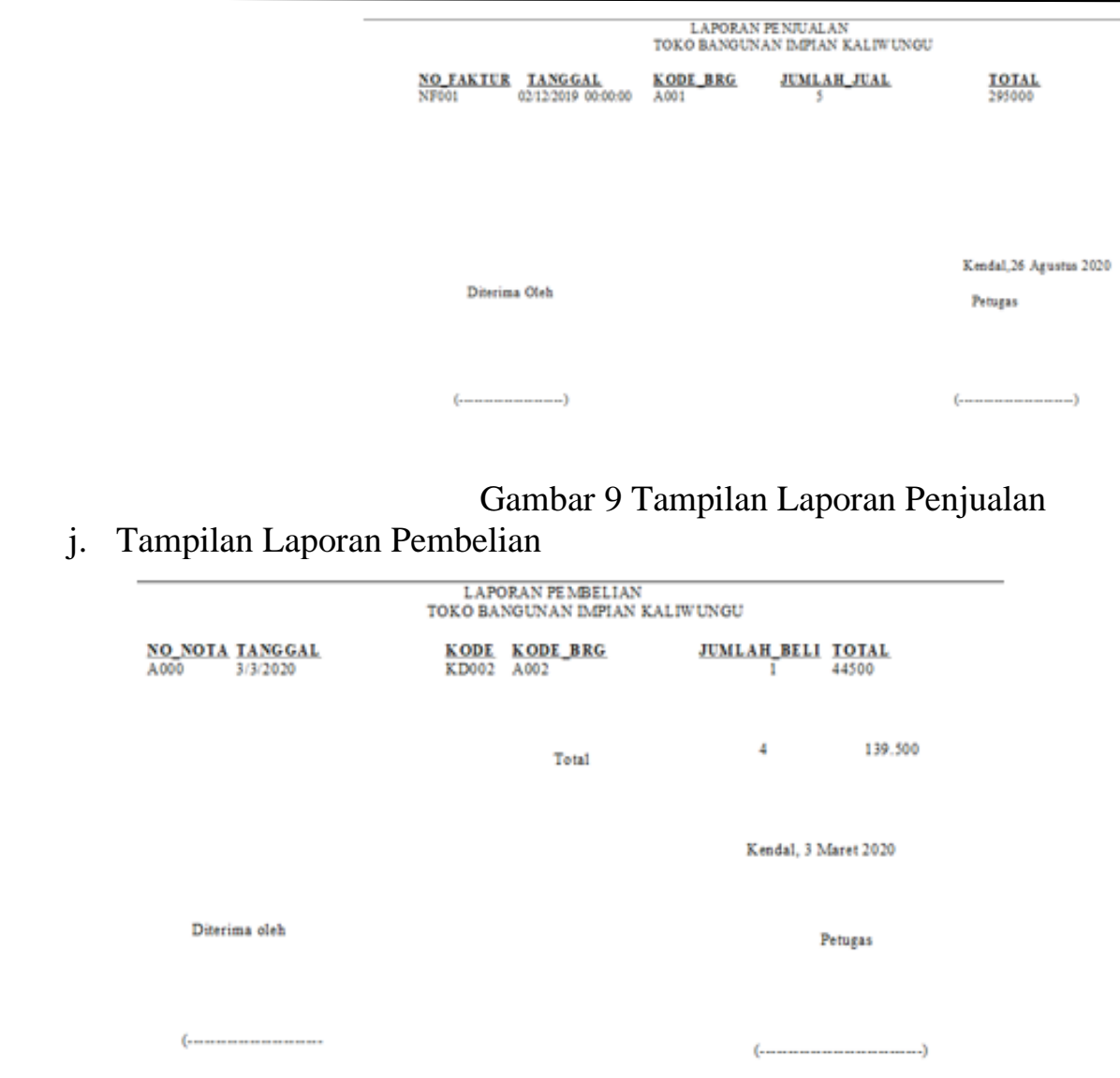

Gambar 10 Tampilan Laporan Pembelian

\section{Conclusion}

Setelah melakukan pengamatan dan penelitian terhadap sistem yang berjalan di Toko Bangunan Impian Kaliwungu, dimana sistem manual yang dijalankan kurang efektif dari segi waktu dan dari segi sumber manusianya.

Untuk mengatasi hal tersebut maka dibutuhkan pembaharuan dari sistem manual yang sedang diterapkan dengan diterapkannya sistem baru. Prosedur penjualan tunai dilaksanakan dengan cara mewajibkan pembeli melakukan pembayaran harga barang lebih dahulu. Sistem dan prosedur penjualan ini belum dilaksanakan berdasarkan metode yang efektif dan efisien.

\section{References}

[1] Mulyadi, .Sistem Akuntansi, Jakarta: Salemba empat, 2013.

[2] A. Susanto, Sistem Informasi Akuntansi, -Struktur-PengendalianResiko-Pengembangan, Bandung: Lingga Jaya, 2013.

[3] W. Sujarweni, Akuntansi Biaya, Yogyakarta: Pustaka Baru Press, 2015.

[4] H. Kartikahadi, Akuntansi Keuangan Berdasarkan SAK Berbasis IFRS, Jakarta: Salemba Emapat, 2016.

[5] E. Siswanto and M. , "Sistem Informasi Pengendalian Intern," Sistem Informasi Pengendalian Intern Atas Piutang Untuk Meminimalkan Jumlah Piutang Tak Trtagih Pada KSU Makmur MAndiri Menggunakan Metode Umur Piutang, 2017.

[6] A. Payitno, emanfaatan Sistem Informasi Perpustakaan Digital Berbasis Website Untuk Para Penulis, Jakarta Timur: AMIKBSI, 2015.

JURNAL ILMIAH KOMPUTERISASI AKUNTANSI Vol. 13, No. 1, Juli $2020: 121$ - 128 